MINTAKAT: Jurnal Arsitektur

Volume 22, Issue 1, 2021, page. 25-41

MINTAKAT: Jurnal Arsitektur

ISSN: 1411-7193 (Print), 2654-4059 (Online)

Universitas Merdeka Malang

\title{
PENGEMBANGAN DAN PENGELOLAAN RUANG TERBUKA HIJAU COASTAL ROAD DI KABUPATEN NUNUKAN
}

\author{
Heru Pitono $^{1}$, A.Tutut Subadyo ${ }^{2}$, Hery Budiyanto ${ }^{2}$ \\ 1)Mahasiswa Program Studi Magister Arsitektur, Universitas Merdeka Malang \\ 2)Dosen Program Magister Arsitektur Universitas Merdeka Malang \\ heru.pitono87@gmail.com
}

\begin{abstract}
ABSTRAK
Ruang Terbuka Hijau Coastal Road (RTH-CR) di Kabupaten Nunukan sangat berperan penting dalam aspek sistem transportasi yang mempunyai fungsi perlindungan, pemanfaatan dan pelestarian lingkungan hidup, saat ini kondisi fisiknya banyak diintervensi kegiatan lain yang bersifat ilegal. Untuk mengembangkannya diperlukan pengelolaan yang mengacu pada ketentuan regulasi yang ada. Penelitian ini bertujuan untuk : 1) Mengidentifikasi karakteristik fisik dan non fisik RTH-CR; 2) Menganalisis dan membuat sintesis model pengelolaan RTH-CR; dan 3) Menyusun model dan desain pengelolaan RTH-CR. Metode yang digunakan pada penelitian ini adalah metode deskriptif kualitatif dengan pendekatan studi kasus. Teknik analisis yang digunakan adalah analisis : Proyeksi Penggunaan Lahan dan Kesesuaian Lahan, Status Lahan, Prioritas Penanganan RTH-CR, dan Kebutuhan Penanganan dan Penyediaan RTH-CR. Hasil penelitiannya adalah : Kondisi fisik dasar RTH-CR pada 3 titik spot dari gerbang Pelabuhan Tunon Taka sampai Simpang Kadir hasil analisis topografinya tergolong datar dengan elevasi reratanya antara 1-5,5 meter; Respon masyarakat terhadap eksistensi RTH-CR, sebagai lokasi yang menarik dan sebagai destinasi wisata menjadi ekpektasi masyarakat yang paling dominan (60,60\%); Pengembangan dan pengelolaan RTH-CR dalam 5 (lima) zona bertema, menyesuaikan iklim tropis, budaya setempat, dan sesuai fungsinya; dan Sistem pengelolaan RTH-CR dilakukan dengan formulasi yang didasarkan pada RTRW Kabupaten Nunukan, regulasi terkait; dan diselenggarakan bersama antara pemerintah, masyarakat dan para pemangku kepentingan lainnya.
\end{abstract}

Kata Kunci : Coastal Road, Nunukan, Pengelolaan, Ruang Terbuka Hijau.

\begin{abstract}
Coastal Road in Nunukan Regency plays an important role in the aspect of the transportation system in Nunukan Regency. Green Open Space Coastal Road in Nunukan Regency is an area in the form of vegetated open space in the coastal road area that has the function of protection, utilization and preservation of the environment. The existence of Green Coastal Road Open Space in Nunukan Regency will increase oxygen production and absorb carbon dioxide, become animal and bird habitats and protect groundwater and reduce the risk of flooding. This study aims to: 1) Identify the physical and non-physical characteristics of the coastal open road green open space; 2) Analyze and make a synthesis of coastal
\end{abstract}


road green open space management models; and 3) Develop a model and design of coastal green road open space management. The method used in this research is descriptive method with a case study approach. The data analysis technique used is to process the results of the field survey and interview survey to determine the design of Green Open Space management. The output of this research is the concept of coastal open road green space management design by adjusting to the Tropical Climate. The design concept of RTH Coastal Road in Nunukan Regency is divided into 5 zones according to existing conditions in the field. So that the appearance of each Coastal Road green zone area varies according to the function and theme. RTH Coastal Road management system is conducted with formulation based on RTRW of Nunukan regency, related regulation, based on RTRW of Nunukan regency, related regulation, and is held together between governments, communities and other stakeholders.

Keywords: Coastal Road, Management, Green Open Space

\section{PENDAHULUAN}

Kabupaten Nunukan terletak di wilayah paling utara dari Provinsi Kalimantan Utara yang berada pada wilayah perbatasan negara yang didalam Peraturan Pemerintah Nomor 26 Tahun 2008 Rencana Tata Ruang Wilayah Nasional (RTRWN) ditetapkan sebagai Kawasan Strategis Nasional (KSN) wilayah perbatasan negara. Konsekuensinya kegiatan penataan ruang dan pembangunan prasarana pendorong tumbuhnya pusat pertumbuhan baru (border city) mendapat prioritas utama. Salah satu prioritas di pulau Nunukan sebagai ibukota Kabupaten Nunukan adalah perencanaan pembangunan ruang terbuka hijau coastal road (RTH-CR). RTH-CR dalam pengertian yang dirujuk dari Undang-undang Republik Indonesia Nomor 26 tahun 2007 tentang Penataan Ruang adalah ruang terbuka hijau memanjang/jalur dalam kota atau pada suatu wilayah. Menurut Simonds and Starke (2006), ruang terbuka hijau jalur dapat berupa waterfront (tepian pantai, tepian danau, tepian sungai), blueways (aliran sungai, aliran air, hamparan banjir), dan greenways (jalan bebas hambatan, jalan-jalan di taman, koridor transportasi, jalan setapak, jalan sepeda, dan jogging track). Masing-masing tipe berbeda efektifitasnya dalam mengurangi suhu udara, pencemaran udara, proteksi lingkungan, dan lain-lain (A.T Subadyo, 2010; A.Tutut Subadyo, Tutuko, \& Jati, 2019; Zain, 2002).

Berdasar kajian Irwan (1994) RTH yang menyebar dengan berbagai tingkatan vegetasi (rumput, semak dan pohon) dapat mengurangi kebisingan (6\%-30\%), debu (38\%-68\%), dan suhu udara di bawah tajuk $\left(0.1-0.5^{\circ} \mathrm{C}\right)$. Hal yang sama di ungkap Misawa (1994) tentang efektivitas jalur hijau dengan lebar lebih dari $2 \mathrm{~km}$, dengan kombinasi vegetasi rumput, semak dan pohon mampu meredam 75\% debu perkotaan. Hasil kajian Purnomohadi (1995) terhadap peran RTH dalam pengendalian kualitas udara menjelaskan bahwa: RTH mampu menekan emisi $\mathrm{CO}, \mathrm{NOx}$ dan $\mathrm{Pb}$ dari sektor transportasi (90\%), industri (7\%), 
sampah kota $(3 \%)$ dan rumah tangga, sehingga secara tidak langsung reduksi emisi gas mengurangi dampak pemanasan lokal, maupun regional.

Dengan demikian RTH-CR sebagai ruang terbuka hijau dapat berfungsi sebagai: (1) koridor transportasi; (2) sarana untuk menjaga kelangsungan fungsi ekosistem dan kelestarian lingkungan; paru-paru kota; sarana menciptakan penghijauan, kesegaran, kesehatan, kebersihan, dan keindahan kota; sarana untuk memperbaiki iklim mikro; daerah resapan; barier angin; dan ruang mitigasi bencana (A.T Subadyo, 2010). Jika dipandang bahwa RTHCR adalah sebuah green belt (sabuk pantai), maka peran atau fungsi dalam mereduksi tsunami oleh Tanaka (2007) dalam Diposaptono (2008) dinyatakan sebagai: (1) perangkap, yaitu untuk menghentikan kayu yang hanyut (pohon tumbang, dll), reruntuhan (rumah yang hancur, dll) dan puing lainnya (perahu, dll); (2) peredam energi tsunami, yaitu efek untuk mengurangi kecepatan aliran air, tekanan aliran, dan kedalaman genangan air; (3) pegangan, yaitu untuk menjadi sarana penyelamatan diri bagi orang-orang yang tersapu oleh tsunami dengan cara berpengangan pada cabang-cabang pohon; pegangan, yaitu untuk menjadi sarana penyelamatan diri bagi orang-orang yang tersapu oleh tsunami dengan cara berpengangan pada cabang-cabang pohon ; dan, (4) pembentuk gumuk pasir, yaitu untuk mengumpulkan pasir yang tertiup angin dan membentuk gumuk/bukit, yang bertindak sebagai penghalang alami terhadap tsunami.

Dalam perencanaannya suatu RTH-CR dipersyaratkan sekurang-kurangnya memenuhi 10 (sepuluh) advantage (A.T Subadyo, 2010; A.T Subadyo \& Poerwoningsih, 2017; A.Tutut Subadyo, Tutuko, \& Cahyani, 2018) yakni sebagai : (1) support local economies, yang dapat mendukung perekonomian setempat dan para pedagang kaki lima (PKL) dan menumbuhkan perekonomian sekitar; (2) attract business investments, yaitu adanya ketertarikan investor dari luar untuk mengembangkan bisnisnya; (3) attract tourism, dapat mengundang turis dari luar daerah; (4) provide cultural opportunities, adanya peluang budaya daerah yang dikembangkan dan diperkenalkan secara lingkup Nasional maupun Internasional; (5) encourage voluunterism, timbulnya ketertarikan pihak luar yang bisa menyediakan diri sebagai tenaga sukarelawan ; (6) reduce crime, untuk mengurangi tingkat kriminalitas; (7) improve pedestrian safety, terjaminnya keamanan; (8) increase use of public transportation, peningkatan penggunaan transportasi umum; (9) improve public health, terjaminnya kesehatan; dan (10) improve the environment, peningkatan kualitas lingkungan agar sesuai dengan fungsinya.

Suatu RTH didalam performansinya perlu mempertimbangkan indikator: (1)identitas lingkungan (mampu membangkitkan kesan yang mendalam bagi warga kota akan ciri khas suatu kawasan); (2) orientasi lingkungan (patokan arah menuju suatu tempat); (3) keindahan 
tata hijau (nilai kualitas visual vegetasi yang memiliki strata banyak, tutupan yang rapat, dan keanekaragaman tinggi), dan (4) keserasian tata bangunan (memperhatikan keserasiannya dengan tata bangunan sekitar atau area terbuka diantara komponen penyusun tata ruang lainnya), serta (5) peningkatan interaksi sosial antar warga (sarana rekreasi, sarana pendidikan, laboratorium hidup, sarana pejalan kaki) (Budihardjo \& Hardjohubojo, 1993; Grey \& Deneke, 1978). Pada umumnya RTH CR yang berstrata, keanekaragaman tinggi, jumlah yang banyak, dan ditata dengan baik akan memberikan kenyamanan lebih baik, dengan demikian akan meningkatkan kinerja RTH CR tersebut. Kelima indikator tersebut sangat relevan pula untuk menilai kinerja unsur tata ruang dikaitkan dengan peran RTH CR sebagai unsur lingkungan.

RTH-CR di Kabupaten Nunukan diharapkan akan sangat berperan penting dalam aspek sistem transportasi yang menghubungkan terminal dan dermaga di Pelabuhan Tunon Taka menuju pusat perkotaan, dan juga berperan meningkatkan produksi oksigen, menyerap karbondioksida, menjadi habitat hewan dan burung serta menjaga air tanah dan mengurangi resiko terjadinya banjir. Fungsi lain dari adalah RTH-CR tersebut adalah fungsi perlindungan, pemanfaatan dan pelestarian lingkungan hidup. Saat ini lokus dari RTH-CR di Kabupaten Nunukan merupakan daerah yang identik dengan kawasan kumuh, ketidakteraturan tapak dan bangunan, serta adanya dermaga bongkar muat material dan tempat penjemuran rumput laut secara ilegal. Disamping itu kondisi biofisiknya merupakan daerah pesisir pantai yang kering, panas, serta terancam abrasi, sedimentasi, penurunan kualitas, dan kerusakan lingkungan.

Oleh karena itu, pengelolaan RTH-CR di Kabupaten Nunukan penting untuk dilakukan, selain untuk menambah prosentase jumlah RTH, juga bisa diproyeksikan menjadi objek atau destinasi wisata tepi pantai di daerah terdepan batas negara. Sekait dengan itu, maka RTH-CR di Kabupaten Nunukan membutuhkan manajemen atau pengelolaan agar peran dan fungsinya dapat optimal. Menurut Aji (2000), Nurisjah, Setiahadi, Zain, \& Qadarian, (2005) dan A.Tutut Subadyo et al. (2019) pengelolaan RTH-CR pada dasarnya ditopang oleh 3 pilar utama, yaitu : (1) instrumen produk rencana tata ruang yang mengakomodasi keberadaan RTH-CR; (2) instrumen peraturan perundangan yang mendukung keberadaan RTH-CR; dan (3) praktek pengelolaan RTH-CR yang dikembangkan.

\section{METODE PENELITIAN}

Penelitian ini menggunakan metode deskriptif dengan pendekatan studi kasus. Pengumpulan data dilakukan dengan cara observasi lapangan, diskusi, wawancara, menelusuri berbagai sumber pustaka seperti hasil penelitian, publikasi ilmiah dan dokumen 
ilmiah dari instansi terkait di Kabupaten Nunukan. Data yang dikumpulkan dibagi dalam tiga kelompok yaitu data alokasi RTH-CR potensial sebagai green belt, luas serta keberadaan RTH-CR, dan luas RTH-CR yang direncanakan sebagai koridor transportasi dan ruang publik. Ada 4 (empat) teknik analisis data yang digunakan dalam penelitian ini yaitu :

1. Analisis Proyeksi Penggunaan Lahan dan Kesesuaian Lahan : untuk menentukan proyeksi penggunaan lahan dan kesesuaian lahan dalam pengelolaan RTH-CR dengan given dari kebijakan dan hasil analisis penggunaan lahan berdasarkan tata ruang (RTRW) di Kabupaten Nunukan.

2. Analisis Status Lahan : untuk mengidentifikasi kepemilikan dan legalitas lahan dalam rangka pengembangan dan pengelolaan RTH-CR berdasarkan sumber data status lahan eksisting.

3. Analisis Prioritas Penanganan RTH-CR : untuk menentukan tingkat urgensi penanganan RTH-CR dengan melakukan skoring dengan beberapa parameter (penggunaan lahan, kepadatan bangunan, kerapatan vegetasi, suhu dan kelembaban, dan jarak antar jalan utama yang membedakan banyak sedikitnya polusi udara).

4. Analisisi Kebutuhan Penanganan dan Penyediaan RTH-CR : untuk menentukan kebutuhan RTH-CR dan penyediaannya berdasarkan pedoman Peraturan Menteri Pekerjaan Umum Perumahan Rakyat Nomor 05 tahun 2008 tentang Pedoman Penyediaan dan Pemnfaatan Ruang Terbuka Hijau di Kawasan Perkotaan (Menteri Pekerjaan Umum, 2008).

Penelitian ini, memiliki beberapa asumsi antara lain sebagai berikut : luas RTH-CR yang dimaksud adalah RTH-CR yang memiliki kemampuan untuk memberi perlindungan terhadap bencana di daerah pesisir; tanpa memperhitungkan perubahan iklim ekstrim yang akhir-akhir ini terjadi; jenis vegetasi yang diintervensikan mempunyai kemampuan sebagai barrier angin, abrasi, sidementasi, dan mitigasi bencana. Sebagaimana diketahui bahwa permasalahan pengelolaan RTH-CR terkait satu sama lain dan kompleks. Oleh sebab itu, konsep penanganan dilakukan dengan berorientasi pada tujuan, secara menyeluruh berdasarkan sistem dengan mempertimbangkan kebutuhan dan peran para pemangku kepentingan.

\section{HASIL PENELITIAN DAN PEMBAHASAN}

\section{Kondisi Fisik}

Kabupaten Nunukan merupakan hasil pemekaran wilayah Kabupaten Bulungan sesuai dengan Undang-undang Nomor 47 tahun 1999, sebagaimana diubah dengan Undang- 
undang Nomor 7 tahun 2000. Luas wilayah Kabupaten Nunukan adalah 14.263,68 km², dan terletak pada posisi $3^{\circ} 15^{\prime} 00^{\prime \prime}-4^{\circ} 24^{\prime}$ 55" Lintang Utara - 115 $22^{\prime} 30^{\prime \prime}-118^{\circ} 44^{\prime}$ 55" Bujur Timur dengan panjang garis perbatasan langsung dengan Negara tetangga (Sabah dan Serawak Malaysia) sepanjang 520.724,43 km. Memiliki luas wilayah $14.424 .750 \mathrm{Ha}$ atau $7,06 \%$ dari total luas Provinsi Kalimantan Utara dan wilayah lautan sejauh 4 mil laut dari garis pantai terluar ke arah laut seluas $1.408,758 \mathrm{~km}^{2}$. Secara administratif wilayah Kabupaten Nunukan dibagi sembilan wilayah, yaitu Kecamatan: (1) Nunukan, (2) Nunukan Selatan, (3) Sebatik, (4) Sebatik Barat, (5) Sebuku, (6) Sembakung, (7) Lumbis, (8) Krayan, dan (9) Krayan Selatan. Penggunaan lahan didominasi oleh wilayah hutan, selain terdapat juga lahan persawahan dan lahan non sawah. Luas kawasan hutan terdiri dari hutan lindung dengan luas lahan 157.387 hektar (11,7\% dari luas wilayahnya), taman Nasional "Kayan Mentarang" seluas 303.682 hektar, kawasan hutan 538.130 hektar, areal penggunaan lain 582.938 hektar.



Gambar .1. Peta Pola Ruang Kabupaten Nunukan dan Arah Perkembangan Pulau Nunukan Sumber :Bappeda Kabupaten Nunukan, 2012 
Kawasan RTH Kabupaten Nunukan memiliki luas kurang lebih 845 hektar yang terdiri dari RTH publik dan RTH privat. RTH publik tersebar di kawasan perkotaan memiliki luas keseluruhan yaitu 163 hektar atau $30 \%$ dari luas kawasan perkotaan yang terdiri atas RTH Areal (taman seluas 2 hektar, TPU seluas 10 hektar, Hutan Kota seluas 13 hektar dan lapangan olahraga seluas 70 hektar) dan RTH Strip/Jalur (sempadan jalan seluas 53 hektar dan sempadan sungai seluas 15 hektar). Jalan Coastal Road merupakan salah satu jalan kolektor yang mempunyai panjang kurang lebih $5 \mathrm{~km}$ (mulai Pelabuhan Tunon Taka sampai dengan Simpang Kadir) dengan lebar jalan 30 meter dengan luasan RTH-CR (sebelah kanan dan kiri jalan) seluas $60.000 \mathrm{M}^{2}$ (Master Plan RTH Kabupaten Nunukan, 2018).

RTH-CR Kabupaten Nunukan berada pada koridor jalan pesisir pantai Nunukan (Ring Road Pulau Nunukan) dengan panjang sekitar $12 \mathrm{~km}$, dengan lebar 30 meter, dengan pedestrian selebar 20 meter. Penelitian dilakukan pada ruas Stasiun Gerbang Pelabuhan Tunon Taka sampai Stasiun Simpang Kadir sepanjang 4800 meter. Berdasarkan Peraturan Daerah Nomor 19 Tahun 2012 tentang RTRW Kabupaten Nunukan 2012-2032, RTH-CR ini akan diisi kegiatan permukiman eksklusif dan perdagangan serta jasa, dan diharapkan dapat mempercepat laju pertumbuhan ekonomi serta menambah daya tarik kawasan wisata Kabupaten Nunukan. 

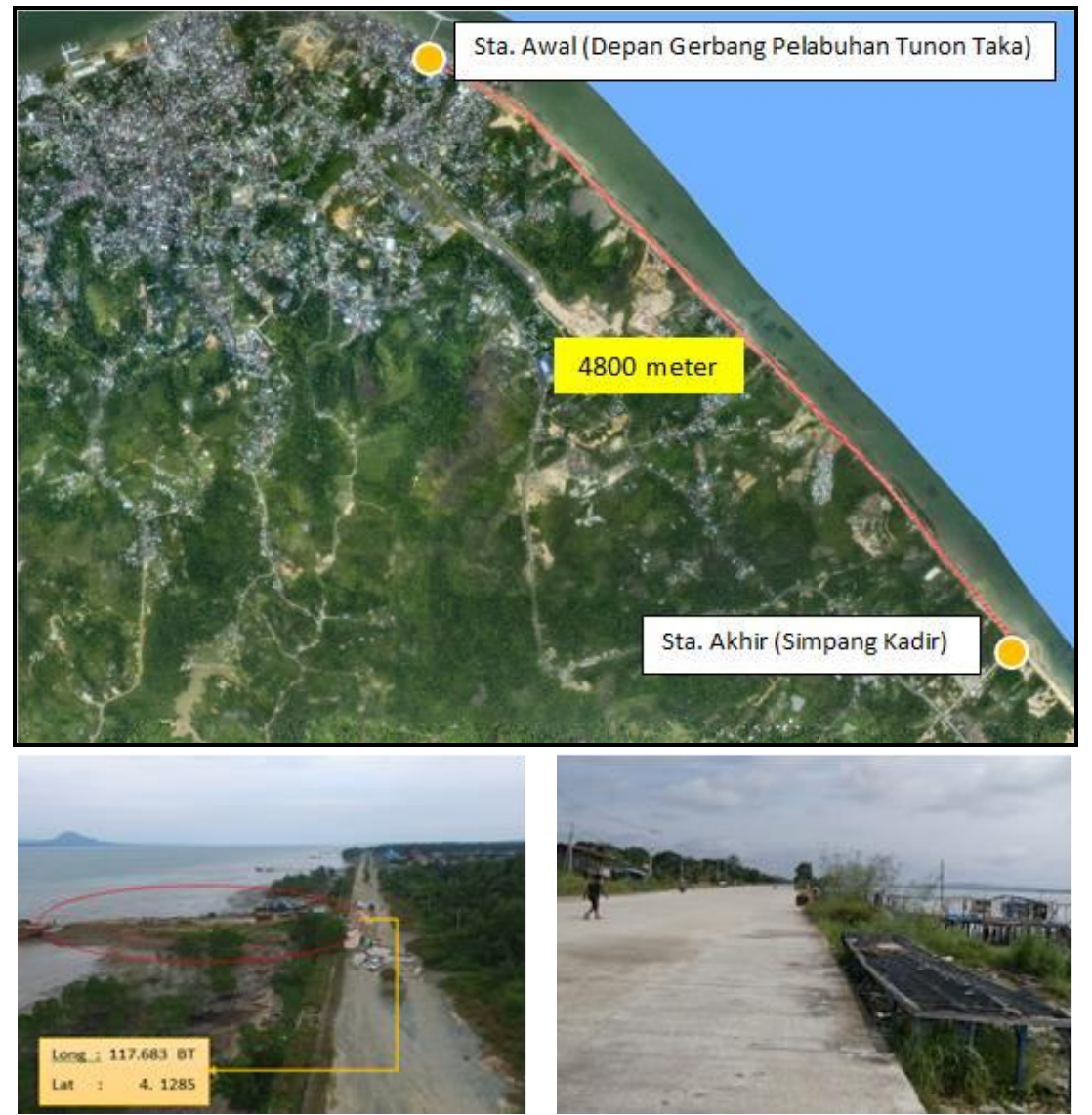

Gambar .2. RTH-CR ruas Stasiun Pelabuhan Tunon Taka - Stasiun Simpang Kadir, Pulau Nunukan (terdapat tempat penjemuran rumput laut dan dermaga bongkar muat barang ilegal )

Sumber : Survey Foto Udara, Tahun 2019

Ketentuan yang dipersyaratkan pada zonasi RTH-CR meliputi : konservasi lingkungan, peningkatan keindahan kota, rekreasi, penyeimbang guna lahan industri dan permukiman, serta fasilitas umum yang menunjang kegiatan rekreasi. Dengan kata lain keberadaan RTHCR mempunyai tujuan dan manfaat yang besar bagi peningkatan kualitas lingkungan, kelestarian, keseimbangan, kelangsungan, kesehatan dan kenyamanan, masyarakat. Namun secara faktual di sepanjang RTH-CR ada beberapa titik ditemukan permukiman nelayan yang penjemuran rumput laut ilegal, 2 titik lokasi aktivitas bongkar muat barang (dermagadermaga kecil ilegal). Pada beberapa titik badan jalan dari RTH-CR mengalami ambles akibat abrasi laut/sungai.

Hasil analisis visual kondisi fisik dasar RTH-CR berdasarkan foto udara, diperoleh 3 (tiga) jenis data, yaitu : (1) Mozaik Orthophoto; (2) Digital Terrain Model (DTM) / Data Kontur, (3) 3D Model. Berikut disajikan hasil analisis pada pada 3 titik spot pada : Sta. 0+000 
(Stationing awal); dari gerbang Pelabuhan Tunon Taka sampai ke arah timur sejauh \pm 580 meter dengan hasil topografi tergolong datar dengan elevasi antara 1-7 meter, Sta. 0+980 Sta.2+475 ke arah tenggara hasil topografinya tergolong datar dengan elevasi antara 1-6 meter, dan Sta. 3+820 - Sta.4+800 (stasiun akhir penelitian) hasil topografinya tergolong datar dengan elevasi antara 1-5,5 meter.
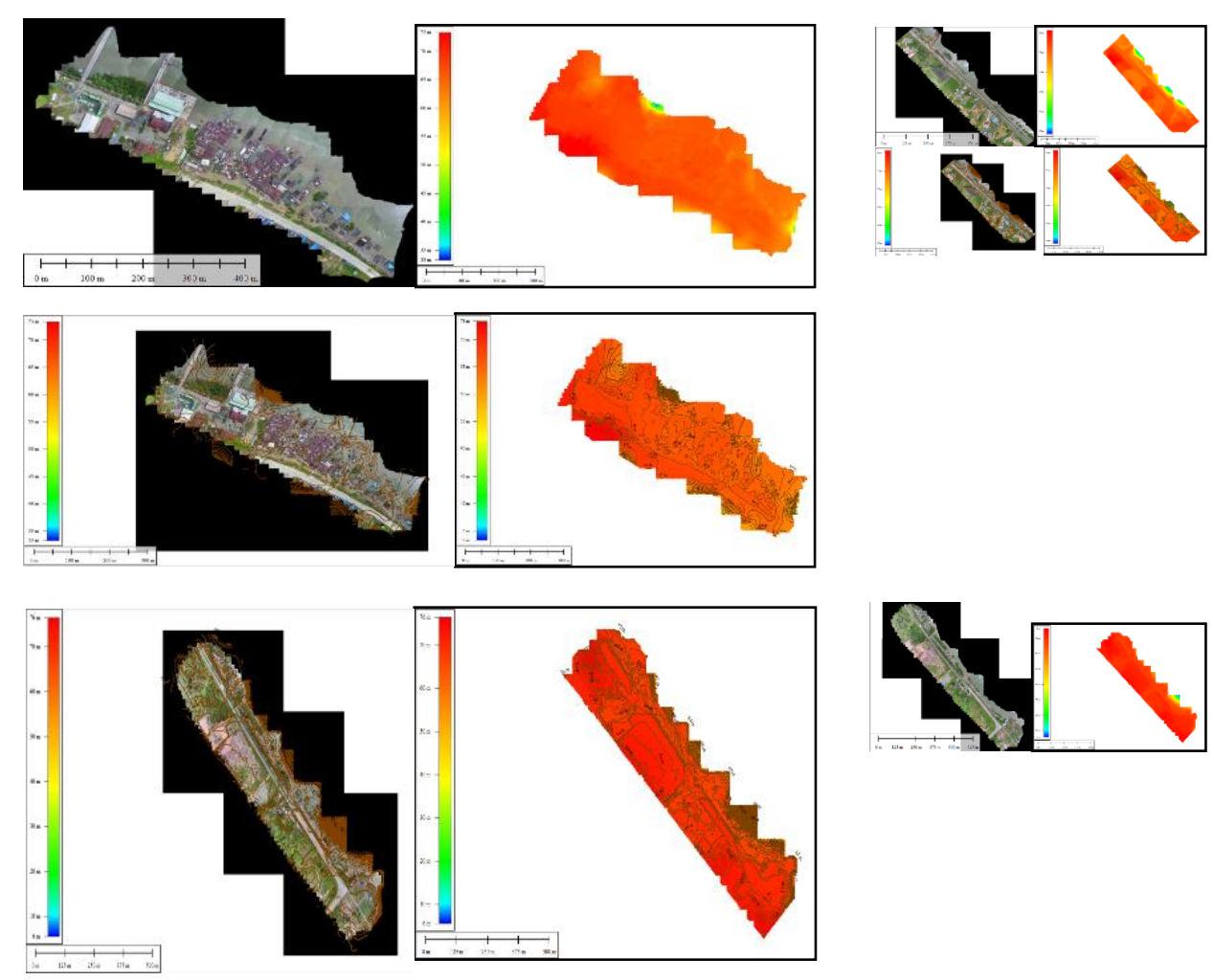

\section{Gambar 3. Overlay data Mozaik Orthophoto, Digital Terrain Model, Interval $1 \mathrm{~m}$ Sta.0+000 - Sta. 4+800 Sumber : Pengukuran Lapangan, 2019}

\section{Preferensi Publik}

Keberadaan RTH-CR saat ini sudah menarik masyarakat, yang ditandai kehadiran pengguna pada waktu-waktu tertentu. Pengunjung RTH-CR pada umumnya adalah masyarakat sekitar dan pendatang luar daerah yang melintas kawasan tersebut. Pada sore hari banyak terdapat aktivitas dalam RTH-CR antara lain : aktivitas perdagangan (PKL), aktivitas jogging track, serta kegiatan berkumpul lainnya. Berdasarkan hasil kuesioner yang didistrubusikan serta wawancara, menurut para pengunjung dan pengguna, coastal road yang ada perlu dikembangkan agar dapat berfungsi untuk melindungi abrasi pantai di kawasan tersebut. 
Selain itu mereka juga mengharapkan agar RTH-CR dapat difungsikan sebagai peneduh, pedestrian serta menjadi objek atau destinasi wisata.

Harapan masyarakat terhadap pengelolaan RTH-CR Kabupaten Nunukan dihubungkan dengan ketentuan yang dipersyaratkan oleh pemerintah seperti yang tertuang dalam Peraturan Daerah Nomor 19 Tahun 2012 tentang RTRW Kabupaten Nunukan 2012-2032, memiliki tanggapan yang sangat positif. Respon tersebut bermakna sangat positif dalam rencana pengembangan RTH-CR Nunukan di masa mendatang. Dengan kata lain respon masyarakat terhadap pengelolaan RTH-CR adalah sangat diperlukan untuk menentukan langkah-langkah pengelolaannya secara langsung maupun tidak langsung terhadap kelestarian fungsi lingkungan. Sebagaimana diketahui bahwa kenyamanan pengunjung (sosiologis dan klimatologis) pada suatu area rekreasi atau taman menjadi prasyarat dasar yang menunjang aktivitasnya pada RTH-CR.

Tabel 1. Harapan masyarakat terhadap pengelolaan RTH-CR Nunukan

\begin{tabular}{|c|c|c|c|}
\hline No & Pertanyaan & Prosentase & Kesimpulan \\
\hline 1 & $\begin{array}{l}\text { Ketersediaan peneduh (perluasan area penghijauan melalui } \\
\text { penanaman pohon peneduh bertajuk lebar, berbunga } \\
\text { berwarna sehingga area menjadi teduh, nyaman, estetis) }\end{array}$ & $28,28 \%$ & Sangat diperlukan \\
\hline 2 & $\begin{array}{l}\text { Kondisi tanah eksisting (pemilihan jenis dan komposisi } \\
\text { vegetasi yang tepat untuk resapan - rimbun, perakaran } \\
\text { dalam, dan dapat memperbaiki struktur tanah) }\end{array}$ & $11,11 \%$ & $\begin{array}{l}\text { Kondisi yang ada perlu } \\
\text { diperbaiki }\end{array}$ \\
\hline 3 & $\begin{array}{l}\text { Akses menuju pantai (penataan aksesibilitas area waterfront } \\
\text { menuju bidang pantai) }\end{array}$ & $6,06 \%$ & $\begin{array}{l}\text { Perlu diperbaiki dan } \\
\text { ditingkatkan }\end{array}$ \\
\hline 4 & $\begin{array}{l}\text { Pemandangan Tepi Pantai (intensifikasi sebagai sabuk hijau } \\
\text { dengan penanaman vegetasi berlapis sepanjang pantai) }\end{array}$ & $8,08 \%$ & $\begin{array}{l}\text { Perlu penataan dan } \\
\text { perbaikan }\end{array}$ \\
\hline 5 & $\begin{array}{l}\text { Batas sisi darat dan sisi air (desain area batas darat-air yang } \\
\text { lebih attractive dan dinamis) }\end{array}$ & $9,09 \%$ & $\begin{array}{l}\text { Kondisi yang ada tidak } \\
\text { menarik, perlu intervensi } \\
\text { desain yang atraktif }\end{array}$ \\
\hline 6 & Titik Atraksi (desain "magnet" untuk attractive spot) & $10,10 \%$ & $\begin{array}{l}\text { Memerlukan desain sebagi } \\
\text { attractive spot }\end{array}$ \\
\hline 7 & $\begin{array}{l}\text { Ketersediaan pedestrian (pedestrian semi massif, } \\
\text { memungkinkan penempatan unsur hijau) }\end{array}$ & $15,15 \%$ & $\begin{array}{l}\text { Dibutuhkan desain yang } \\
\text { menunjang fungsi RTH-CR }\end{array}$ \\
\hline 8 & $\begin{array}{l}\text { Ketersediaan penerangan jalan (memanfaatkan teknologi } \\
\text { solar system) }\end{array}$ & $12,12 \%$ & $\begin{array}{l}\text { Diperlukan untuk } \\
\text { menopang keamanan, } \\
\text { kenyamanan dan } \\
\text { keindahan }\end{array}$ \\
\hline & Total & $100,00 \%$ & \\
\hline
\end{tabular}

Sumber : Hasil Kuesioner Penelitian, 2019

Bertolak dari pemahaman tersebutlah selanjutnya dibangun konstruksi pengembangan RTH-CR Nunukan, dimana dampak positifnya seperti membantu mengurangi cemaran 
udara, penghasil oksigen, pereduksi karbondioksida, mengurangi pemanasan global, tempat rekreasi, relaksasi dan refreshing, dioptimalisasikan. Respon masyarakat terhadap pengaruh positif pengembangan dan pengelolaan RTH-CR Nunukan tersaji dalam tabel berikut.

Tabel 2. Pengaruh Positif terhadap pengelolaan RTH-CR Nunukan

\begin{tabular}{clc}
\hline No & \multicolumn{1}{c}{ Pengaruh Positif adanya RTH-CR Nunukan } & Prosentase \\
& & \\
\hline $\mathbf{1}$ & Lokasi menjadi menarik & $40,40 \%$ \\
\hline $\mathbf{2}$ & Bisa dijadikan objek atau destinasi wisata & $20,20 \%$ \\
\hline $\mathbf{3}$ & Udara menjadi segar & $16,16 \%$ \\
\hline $\mathbf{4}$ & Tempat berlindung dan bernaung dari matahari & $12,12 \%$ \\
\hline $\mathbf{5}$ & Adanya pedestrian yang nyaman dan manusiawi & $11,11 \%$ \\
\hline & Total & $100,00 \%$ \\
\hline
\end{tabular}

Sumber : Hasil Kuesioner Penelitian, 2019

Dari tabel 2 di atas dapat diinterpretasikan bahwa lokasi yang menarik dan menjadi objek atau destinasi wisata merupakan ekpektasi masyarakat yang paling dominan (60,60\%) terhadap eksistensi RTH-CR Nunukan nantinya.

\section{Pengembangan dan Pengelolaan RTH-CR Nunukan}

Berdasarkan hasil persepsi, preferensi publik terhadap RTH-CR serta analisis terhadap kondisi dan karakteristik biofisiknya, maka arah pengembangan RTH-CR Nunukan diproyeksikan sebagai ruang terbuka hijau dengan variabel dan parameter sebagai berikut : (1) ketersediaan peneduh (perluasan area penghijauan melalui penanaman pohon peneduh bertajuk lebar, berbunga berwarna sehingga area menjadi teduh, nyaman, estetis), (2) kondisi tanah (pemilihan jenis dan komposisi vegetasi yang tepat untuk resapan - rimbun, perakaran dalam, dan dapat memperbaiki struktur tanah), (3) akses menuju pantai (penataan aksesibilitas area waterfront menuju bidang pantai), (4) view yang menarik (intensifikasi sebagai sabuk hijau dengan penanaman vegetasi berlapis sepanjang pantai), (5) kurang menariknya batas darat dan air (desain area batas darat-air yang lebih attractive dan dinamis), (6) titik atraksi (desain "magnet" untuk attractive spot), (7) ketersedian pedestrian (pedestrian semi massif, memungkinkan penempatan unsur hijau), dan (8) ketersediaan street \& site furniture, utamanya penerangan jalan (memanfaatkan teknologi solar system).

Pengembangan RTH-CR Kabupaten Nunukan hasil analisis kondisi fisik pada 3 titik spot diawali dengan membaginya menjadi 5 (lima) zona (Zona A sampai dengan Zona E) dengan masing-masing zona dikembangkan dengan tema yang berbeda-beda. Hal ini dimaksudkan untuk menampilkan beberapa tematik pada zona RTH-CR, sehingga pada masing-masing zona memiliki ciri khas/keunikan tersendiri dan bersifat eksotis. 




Gambar 4. Peta Pembagian Zona RTH-CR Kabupaten Nunukan

Sumber : olah data Foto udara, 2019

Zona A adalah zona RTH-CR yang pertama dilewati setelah memasuki pintu gerbang. Untuk memberikan suasana yang lebih "ramah" maka diperlukan tampilan landscape yang lebih atraktif dengan bentuk yang dinamis dan permainaan warna yang beragam, sehingga secara psikologis bisa mengadirkan mood yang lebih baik. Hal ini di representasikan dari pemilihan jenis pohon dan semak yang bertema "Colourfull Flowering Plants". Elemen softscape tanaman pengisi adalah jenis tabebuya. Tanaman ini merupakan pohon lindung yang mampu berbunga dan memiliki bentuk bunga yang bagus dan bergerombol. Sedangkan unsur hardscape yang ditampilkan pada zona A adalah pathway (A. Tutut Subadyo, 2007) yaitu jalan setapak yang menghubungkan antara jalan raya dengan bidang taman di sepanjang RTH-CR. Bentuk jalan setapak dibuat melengkung dan dinamis. Material finishingnya dari keramik berwarna terang bertekstur kasar supaya tidak licin. Unsur hardscape lainnya adalah pergola di sisi kanan. Pergola berbahan kayu dengan kombinasi tanaman merambat diatasnya bisa menggantikan fungsi pohon sebagai peneduh. 

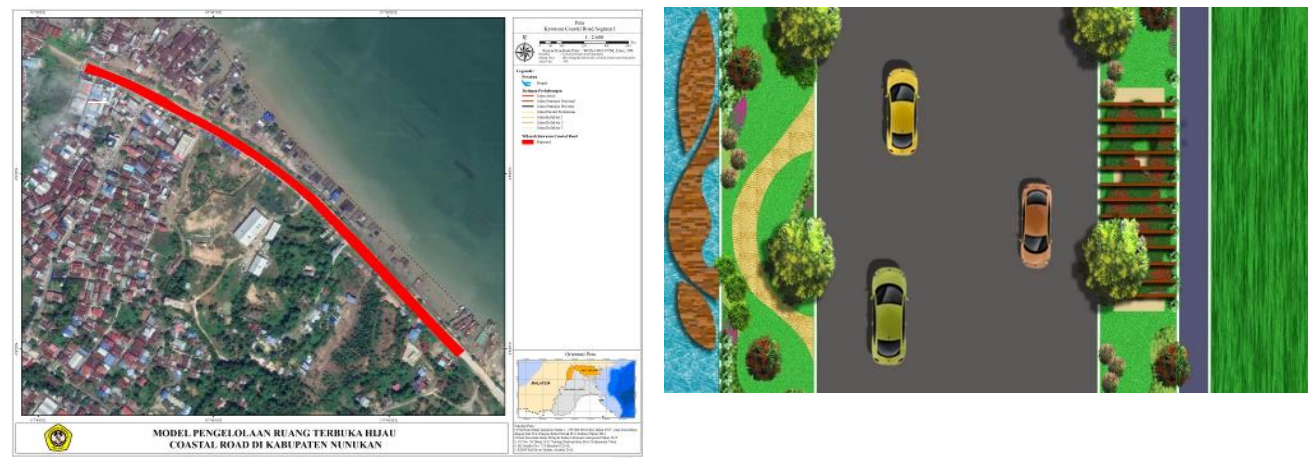

Gambar .5. Zona A dan Desain Prototype RTH-CR Zona A Sumber : Usulan Peneliti, 2019

Zona B mengusung tema jenis tanaman tropis khas pesisir pulau, yang didominasi oleh jenis kelapa dan palm. Hal ini direpresentasi dari pemilihan jenis pohon kelapa, palm yang ditata dengan pola geometris sepanjang zona B dan untuk menyeimbangkan warnanya, unsur warna diaplikasikan pada semak di bawahnya. Tema pada zona ini adalah "Tropical Coco and Palms". Elemen softscape tanaman pengisi adalah jenis pohon kelapa. Sedangkan unsur hardscape yang ditampilkan pada zona B adalah pathway (A. Tutut Subadyo, 2007), yaitu jalan setapak yang menghubungkan antara jalan raya dengan bidang taman di sepanjang RTH-CR. Bentuk jalan setapak di zone ini dibuat lurus, tegak, mengikuti sifat simetrikal pohon kelapa.
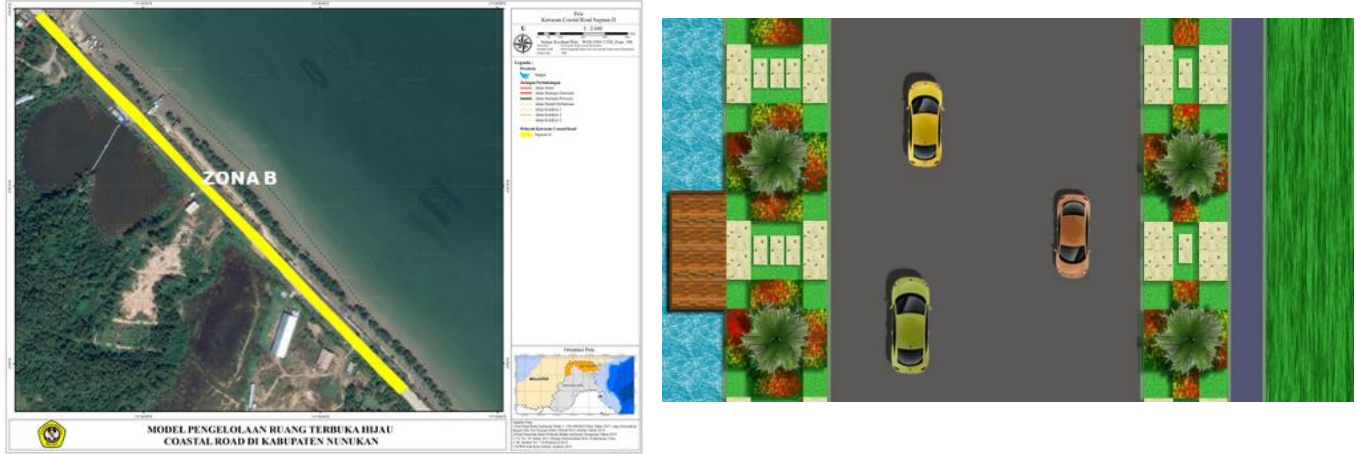

Gambar.6. Zona B dan Desain Prototype RTH-CR Zona B

Sumber : Usulan Peneliti, 2019

Pada Zona $\mathrm{C}$ terdapat banyak permukiman penduduk dan dermaga bongkar muat, tema taman berubah menjadi area serba hijau dengan pemilihan pohon jenis ketapang kencana dan hamparan rumput yang dibentuk bergunduk-gunduk, dengan pemilihan shrub dari jenis alang-alang, sehingga menampilkan kesan tropis. Pada zona ini, jogging track meliuk di area yang mendapat naungan keteduhan dari pohon ketapang kencana, dengan material keramik bertekstur kasar dan berwarna terang. Tema pada zona ini adalah "Green Savanna". Elemen softscape tanaman pengisi adalah jenis Pohon ketapang kencana. Sedangkan unsur 
hardscape yang ditampilkan pada zona $\mathrm{C}$ adalah pathway yaitu jalan setapak yang berfungsi sebagai jogging track (A. Tutut Subadyo, 2007), karena jalur setapaknya sambung menyambung sepanjang zona ini. Material finishingnya dari keramik berwarna terang bertekstur kasar supaya tidak licin.
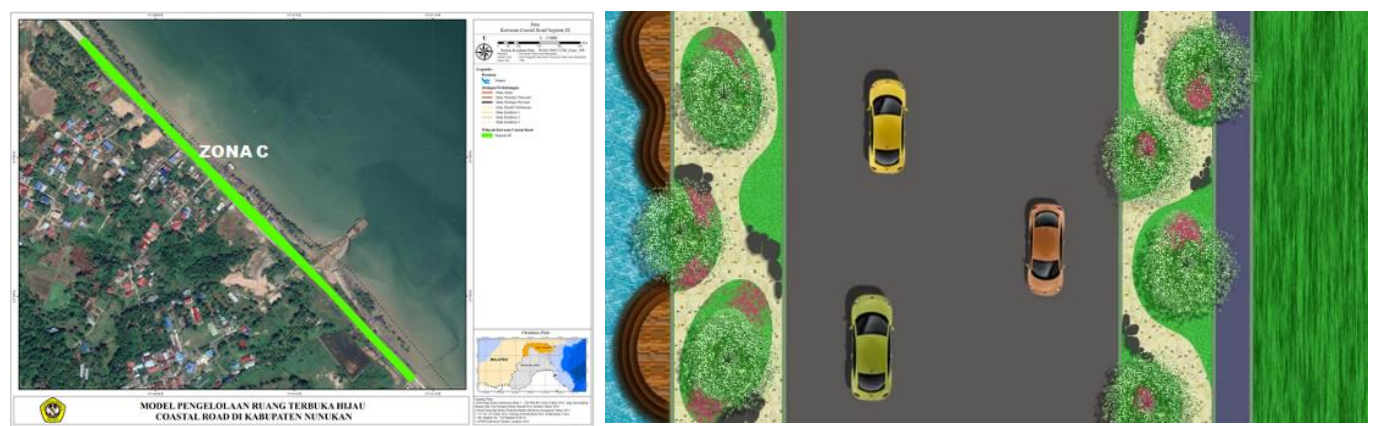

\section{Gambar . 7. Zona C dan Desain Prototype RTH -CR Zona C Sumber : Usulan Peneliti, 2019}

Pada Zona D ada area yang cukup ramai (masjid dan rencana pujasera). Sehingga pada zona D dimanfaatkan dan dikelola sebagai pusat keramaian, dengan merencanakan adanya pelabuhan wisata yang berintegrasi dengan restaurant dan Local floating market yang menjual makanan dan barang khas pulau Nunukan sebagai oleh-oleh. Jenis pohon pada zona D ini lebih diarahkan ke jenis buah-buahan, supaya berkorelasi dengan restaurant apung yang direncanakan tersebut. Tema pada zona ini adalah "Fruity Garden".Elemen softscape tanaman pengisi adalah jenis pohon flamboyan. Pohon ini akan memekarkan bunganya pada saat musim semi dan musim panas. Manfaat tanaman flamboyan yang bentuknya seperti payung dan mempunyai bunga dengan warna-warna cerah yaitu merah, orange, dan kuning ini digunakan sebagai peneduh dan penghias suasana karena keindahannya. Sedangkan elemen hardscape pada zona D adalah pembuatan deck lebar di sisi laut yang berfungsi sebagai pelabuhan wisata, dengan korelasi restaurant dan lokal market sebagai tempat penjualan oleh oleh. Pada zona D ini, fasilitas landscape furniture disiapkan lebih lengkap, termasuk kran air bersih dan toilet umum.


Gambar. 8. Zona D dan Desain Prototype RTH - CR Zona D

Sumber : Usulan Peneliti, 2019 
Zona E adalah zona terakhir dari penelitian RTH-CR, dimana lokasinya berada paling ujung, di bagian persimpangan jalan. Pada kondisi eksisting, tidak ada area komunal yang bisa digunakan. Karena bagian ini adalah bagian yang bisa diakses dari dua arah jalan, untuk itu sangat tepat dimanfaatkan sebagai "vocal point" untuk masyarakat sekitar berkumpul melakukan aktivitas sosialnya secara berkelompok, sehingga tema pada bagian ini adalah "Communal Space". Elemen softscape tanaman pengisi adalah jenis pohon flamboyan. Manfaat tanaman pohon flamboyan yang bentuknya seperti payung dan mempunyai bunga dengan warna cerah yaitu merah, orange, dan kuning ini digunakan sebagai peneduh dan penghias suasana karena keindahannya. Sedangkan elemen hardscape zona E ini adalah pembuatan deck lebar di sisi laut yang berfungsi sebagai communal space, ruang publik terbuka yang bisa dengan bebas dimanfaatkan oleh masyarakat untuk melakukan aktivitas sosialnya secara berkelompok. Misalnya duduk mengobrol, menikmati pertunjukan yang ada di area open theatre, melakukan aktivitas olahraga dengan alat-alat outdoor gym, maupun menemani anaknya di area playground. Pada zona ini, fasilitas landscape furniture disiapkan lebih lengkap, termasuk kran air bersih dan toilet umum.
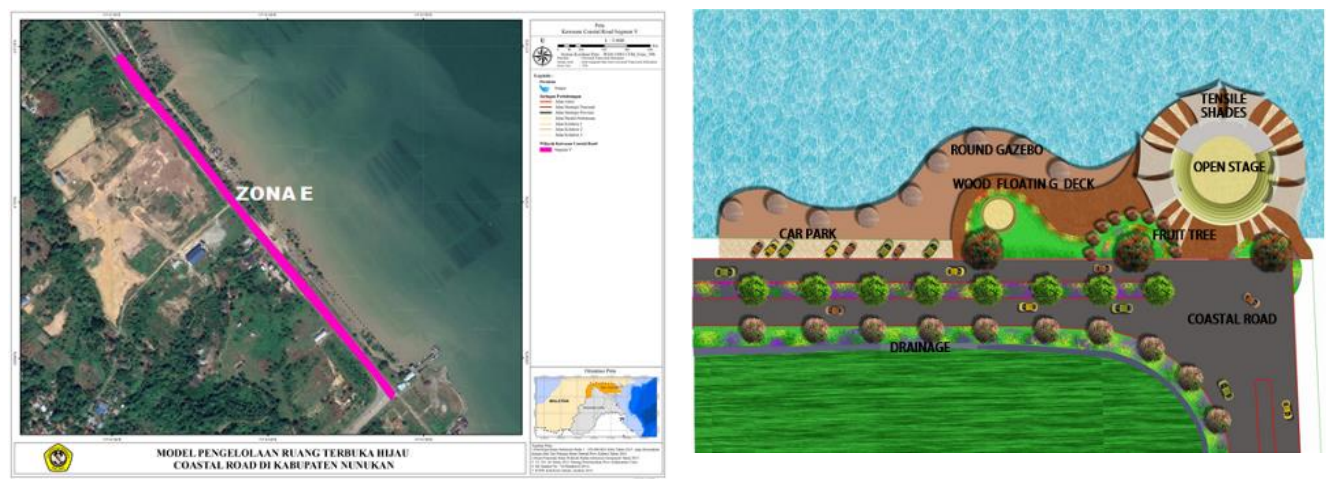

\section{Gambar.9. Zona E dan Desain Prototype RTH-CR Zona E Sumber : Usulan Peneliti, 2019}

\section{SIMPULAN}

Dari hasil analisis dan pembahasan dapat disimpulkan bahwa :

- Kondisi fisik dasar RTH-CR pada 3 titik spot: Sta. 0+000 (stasiun awal); dari gerbang Pelabuhan Tunon Taka sampai ke arah timur sejauh \pm 580 meter dengan hasil topografi tergolong datar dengan elevasi antara 1-7 meter, Sta. 0+980 - Sta.2+475 ke arah tenggara hasil analisis topografinya berdasarkan data Mozaik Orthophoto \& Digital Terrain Model tergolong datar dengan elevasi antara 1-6 meter, dan Sta. 3+820 Sta.4+800 (stasiun akhir penelitian) hasil topografinya tergolong datar dengan elevasi antara 1-5,5 meter.

- Respon masyarakat terhadap eksistensi RTH-CR Kabupaten Nunukan, dimana keberadaannya dinyatakan sebagai lokasi yang menarik dan menjadikannya sebagai destinasi wisata merupakan ekpektasi masyarakat yang paling dominan $(60,60 \%)$. 
- Pengembangan dan pengelolaan RTH-CR Kabupaten Nunukan pada 5 (lima) zona dengan tema yang berbeda-beda, menyesuaikan iklim tropis, budaya setempat, dan sesuai fungsinya, akan bersifat eksotis dan memiliki ciri khas/keunikan tersendiri.

- Sistem pengelolaan RTH-CR Kabupaten Nunukan formulasinya didasarkan pada RTRW Kabupaten Nunukan, peraturan perundangan yang mendukung keberadaan RTH-CR; dan diselenggarakan bersama antara pemerintah, masyarakat dan para pemangku kepentingan lainnya.

\section{REFERENSI}

Aji, A. (2000). Pengelolaan Ruang Terbuka Hijau secara Berkelanjutan (Studi Kasus di Kotamadya Bandarlampung. IPB.

Bappeda Kabupaten Nunukan. (2012). Peraturan Daerah Nomor 19 Tahun 2012, tentang Rencana Tata Ruang Wilayah (RTRW) Kabupaten Nunukan Tahun 2012-2032.

Budihardjo, E., \& Hardjohubojo, S. (1993). Kota Berwawasan Lingkungan. Bandung: Penerbit Alumni.

Diposaptono, S. B. (2008). Hidup Akrab dengan Gempa dan Tsunami. Pedoman Pengelolaan Sabuk Pantai Untuk Mitigasi Tsunami. Jakarta.

Grey, G. ., \& Deneke. (1978). Urban Forestry. New York: John Willey and Sons.

Irwan, Z. . (1994). Peranan Bentuk dan Struktur Hutan Kota terhadap Kualitas Lingkungan Kota: Studi Kasus Lokasi Pemukiman Kota Jakarta. IPB.

Jorgensen, B. ., \& Stedman, R. . (2001). Sense of place as an attitude: lakeshore owners attitudes toward their properties. Journal of Environmental Psychology.

Menteri Pekerjaan Umum. (2008). Peraturan Menteri Pekerjaan Umum Nomor: 05/PRT/M/2008 Pedoman Penyediaan dan Pemanfaatan Ruang Terbuka Hijau Di Kawasan Perkotaan. Indonesia.

Misawa, A. (1994). Studi-Studi Dasar Struktur Tanaman Sabuk Penyangga Tepi Jalan.

Nurisjah, S., Setiahadi, A. M., Zain, \& Qadarian. (2005). Ruang Terbuka Hijau Wilayah Perkotaan. Makalah Diskusi Pengembangan Sistem RTH Di Perkotaan. Bogor: Bappeda.

Purnomohadi, S. (1995). Peran Ruang Terbuka Hijau dalam Pengendalian Kualitas Udara Di DKI Jakarta. IPB.

Simonds, J., \& Starke. (2006). Landscape architecture: A Manual Of Site Planning and Design. 
New York (USA): Mc Graw Hill Book Co.

Subadyo, A. Tutut. (2007). Pathway Corridor as a Place for Informal Settlements, CIB Report Publication 314. CIB General Secretariat.

Subadyo, A.T. (2010). Lanskap Koridor Jalan di Perkotaan sebagaiPembentuk Nilai Lingkungan. Kasus Kota Malang. Institut Teknologi Sepuluh Nopember (ITS) Surabaya.

Subadyo, A.T, \& Poerwoningsih, D. (2017). Design of Integrated Infrastucture Development in Poncokusumo Agropolitan Region Malang Indonesia. Ecology, Environment and Conservation Journal, 23(1), 63-70.

Subadyo, A.Tutut, Tutuko, P., \& Cahyani, S. D. (2018). The Assessment of Inclusive Historical Public Space in Achieving Preservation of Such Areas in Malang, Indonesia. Case Study Public Space Developed During The Dutch Colonial Period. Journal International Review for Spatial Planning and Sustainable Development, 6(4), 72-94.

Subadyo, A.Tutut, Tutuko, P., \& Jati, R. M. B. (2019). Implementation Analysis of Green City Concept Malang - Indonesia. Journal International Review for Spatial Planning and Sustainable Development, 7(2), 36-52.

Zain, A. F. M. (2002). Distribution, Structure and function of Urban green space in Soultheast Asian Mage-cities with special reference to Jakarta Metropolitan Region (JABOTABEK). The University of Tokyo. 